\title{
35. MAGNETIZATION OF VARICOLORED PELAGIC LIMESTONES FROM HOLES 544A AND 547B 1
}

\author{
J. E. T. Channell, Department of Geology, University of Florida ${ }^{2}$
}

\begin{abstract}
Jurassic limestones from Holes 544A and 547B were sampled to determine their magnetic stratigraphy and to compare their magnetic properties with those of Italian limestones of similar age and facies. The recovery at both holes was insufficient for determining a recognizable pattern of magnetozones. However, the presence of reversals at Hole 544A indicates that these limestones were not deposited within the Jurassic "quiet zone" of prolonged normal polarity (Oxfordian-Callovian). Thermal and alternating field demagnetization of these varicolored limestones indicates either single component magnetizations or, in some cases, the superimposition of antiparallel components with differing blocking temperature and coercivity spectra.
\end{abstract}

\section{INTRODUCTION}

The sampling at Hole 544A was conducted in order to obtain the maximum possible sample density to resolve a magnetic stratigraphy. In contrast, the sampling at Hole 547B was directed toward the collection of varicolored samples of differing lithology for a study of variations in magnetization history. The samples were subjected to thermal and alternating field demagnetization treatments and their magnetization was measured with a cryogenic magnetometer.

\section{HOLE 544A}

The Jurassic limestones at Hole 544A (Unit III) are pale reddish brown (10R 5/4) in color with pale yellowish brown (10YR 6/2) and yellowish gray (5Y 7/2) mottling. Forty-three samples were taken from Cores 544A13 to 544A-16 (Fig. 1). The recovery was too poor, and therefore the sampling density too low, to establish a continuous magnetic stratigraphy for these Jurassic rocks. However, the inclination data obtained clearly define several reversals (Fig. 1). The samples were thermally demagnetized in progressive $50^{\circ} \mathrm{C}$ steps from 100 to $550^{\circ} \mathrm{C}$, with additional steps of 575 and $600^{\circ} \mathrm{C}$ for some samples. The resulting demagnetization data are interesting and will be discussed in some detail.

Many of the samples, such as 544A-13-1, $12 \mathrm{~cm}$ (Fig. $2 \mathrm{~A}$ ), show single component decay of the magnetization vector to the origin of the orthogonal projection. The large drop in intensity of the magnetization vector between 300 and $350^{\circ} \mathrm{C}$ in this particular sample is not a general characteristic. The reversed interval at the base of Core 544A-13 (Fig. 1) is characterized by behavior similar to that of 544A-13-1, $110 \mathrm{~cm}$ (Fig. 2A) where the polarity of the magnetization does not change until demagnetization temperatures of $450^{\circ} \mathrm{C}$ are reached. This

\footnotetext{
${ }^{1}$ Hinz, K., Winterer, E. L. et al., Init. Repts. DSDP, 79: Washington (U.S. Govt. Printing Office).

2 Address: Department of Geology, University of Florida, Gainesville, FL 32611
}

temperature suggests that the normal magnetization component in this sample is not viscous in origin, because it is unlikely that a viscous remanent magnetization (VRM) carried by hematite (or any other mineral) could survive demagnetization temperatures in excess of $350^{\circ} \mathrm{C}$ (Dunlop and Stirling, 1977). The normal overprint apparent in this and other samples that feature a high blocking temperature reversed component is probably chemical in origin (CRM) and reflects hematite growth during both a reversed and a subsequent normal polarity interval. The presence of antiparallel hematite CRM's has been observed in rocks of similar facies from Italy (Channell, Freeman, et al., 1982) where it has been demonstrated that the higher blocking temperature component records the older polarity interval. The reversed samples at the top of Core $544 \mathrm{~A}-14$ become reversed after demagnetization at $100^{\circ} \mathrm{C}(544 \mathrm{~A}-14-1,27 \mathrm{~cm}$; Fig. 2A), but the normal overprint is present up to $250^{\circ} \mathrm{C}$. The lower reversed interval in Core 544A-14 (544A-14-2, $14 \mathrm{~cm}$; Fig. 2A) exhibits this same normal overprint but up to temperatures of $400^{\circ} \mathrm{C}$. Another sample from the same reversed interval (544A-14-2, $93 \mathrm{~cm}$; Fig. 2B) shows similar behavior with the normal overprint present at temperatures up to $450^{\circ} \mathrm{C}$. The polarity of the magnetization components is not always unambiguous. For example, the behavior of 544A-14-3, $63 \mathrm{~cm}$ (Fig. 2B) suggests the presence of a high temperature reversed magnetization component, but the vector endpoints are not well defined due to the low magnetization intensities at these high demagnetization temperatures. Another example of ambiguity is seen in 544A-15-3, $88 \mathrm{~cm}$ (Fig. 2C) where the vector endpoints appear to be missing the origin of the orthogonal projection and a reversed magnetization component is not clearly defined. Reversed magnetizations are occasionally apparent at low demagnetization temperatures (544A-15-2, $29 \mathrm{~cm}$; Fig. 2C) but usually reversed magnetizations are only achieved at demagnetization temperatures of $200^{\circ} \mathrm{C}$ or above.

As mentioned above, the pervasive normal overprint seen in samples which feature a high blocking temperature reversed magnetization component is very probably 


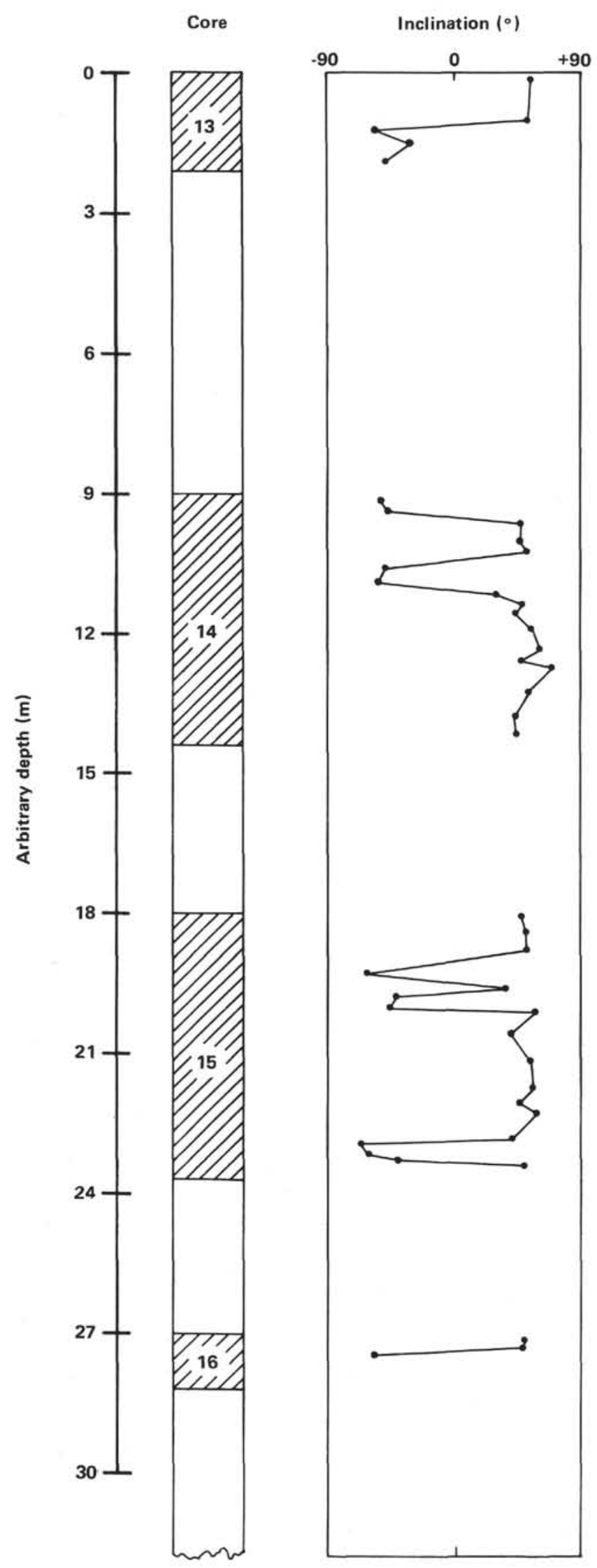

Figure 1. Inclination of the magnetization of samples from Hole 544A calculated from orthogonal projections of thermal demagnetization data. not a VRM and is likely to be a CRM carried largely by hematite. This CRM overprint always has normal polarity. We never see a similar, but reversed, overprint affecting those samples with normal magnetization. One possible conclusion is that all samples have been affected by a particular diagenetic (cementation?) event that was responsible for appreciable hematite growth and occurred in an epoch of normal geomagnetic polarity. The lack of overlap of the blocking temperature spectra of the two antiparallel components (544A-14-2, $14 \mathrm{~cm}$; Fig. 2A) tends to suggest that the two components represent two hematite growth events with distinct grain size spectra rather than a single growth event occurring during two polarity epochs. The high blocking temperature component occasionally survives demagnetization temperatures of 575 or $600^{\circ} \mathrm{C}$ indicating some contribution from hematite. The large drop in magnetization between 500 and $550^{\circ} \mathrm{C}$ (e.g., $544 \mathrm{~A}-14-1,27 \mathrm{~cm}$; 544A-14-1, $106 \mathrm{~cm}$; 544A$14-1,126 \mathrm{~cm}$ (Fig. 2A); 544A-14-3, $41 \mathrm{~cm}$; 544A-14-3, $134 \mathrm{~cm}$; 544A-14-4, $98 \mathrm{~cm}$ (Fig. 2B); 544A-15-3, $123 \mathrm{~cm}$; 544A-16-1, $18 \mathrm{~cm}$ (Fig. 2C)) suggests that the high temperature components are largely carried by magnetite, a detrital mineral in this environment (Channell, Freeman, et al., 1982).

The orthogonal projections of thermal demagnetization data were used to compute the magnetic inclination associated with the high blocking temperature components. Where possible, linear segments of the endpoints of the vertical projection of this component were picked visually and the best-fitting straight line was computed by a least-squares technique. For some samples (e.g., 544A-13-1, $110 \mathrm{~cm}$; Fig. 2A) the high temperature component could not be defined by a linear segment of the projection and a value of inclination was computed from the stable endpoint. The resulting inclination values (Fig. 1) indicate several magnetic reversals. Each core has at least one magnetic reversal and these magnetozones are usually defined by more than one sample. The poor recovery does not allow a magnetic stratigraphy to be established and correlated to the polarity time scale. However, the presence of reversals does tell us something about the age of the rocks. If we can assume that the characteristic magnetizations are primary (and the rock magnetic data would suggest that they are), then the age of these rocks does not coincide with the Jurassic quiet zone, a period of prolonged normal polarity. According to Channell, Ogg, et al. (1982), the Jurassic quiet zone encompasses the Oxfordian and Callovian stages and, therefore, these cores should either be younger than Oxfordian or older than Callovian.

The mean inclination value from these cores can be used to compute the paleolatitude of deposition. Arithmetic means of inclinations of paleomagnetic data consistently underestimate the vector mean inclination. When only the vertical component is known (as in the case of borehole data), the true vector mean inclination can be estimated using a graphic technique (Briden and Ward, 1966) or by iteration, using the arithmetic mean and standard deviation of the inclination data alone (Kono, 1980). With the iteration technique, a mean inclination of $48.2^{\circ}$ is obtained for these cores corresponding to a paleolatitude of deposition of $29.2(\mathrm{dp}=3.2)$. 
544A-13-1, $12 \mathrm{~cm}$

(NRM- $600^{\circ} \mathrm{C}$ )

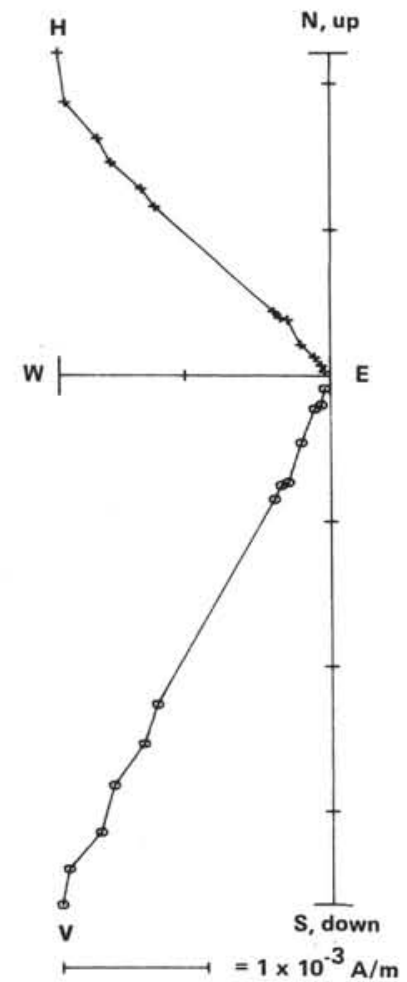

$544 \mathrm{~A}-13-1,110 \mathrm{~cm}$

$\left(350-575^{\circ} \mathrm{C}\right)$

N, up

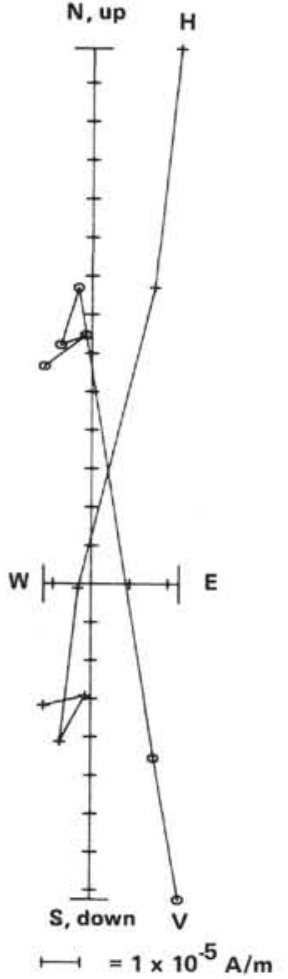

544A-14-1, $126 \mathrm{~cm}$

(NRM-600 ${ }^{\circ} \mathrm{C}$ )

(NRM-600 ${ }^{\circ} \mathrm{C}$ )

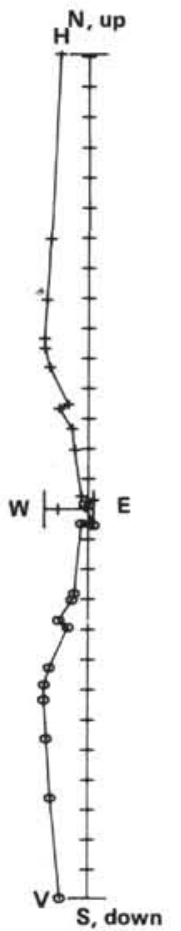

$\longmapsto=1 \times 10^{-4} \mathrm{~A} / \mathrm{m}$

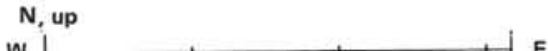

$544 \mathrm{~A} \cdot 14 \cdot 1,27 \mathrm{~cm}$

$\left(100-575^{\circ} \mathrm{C}\right)$

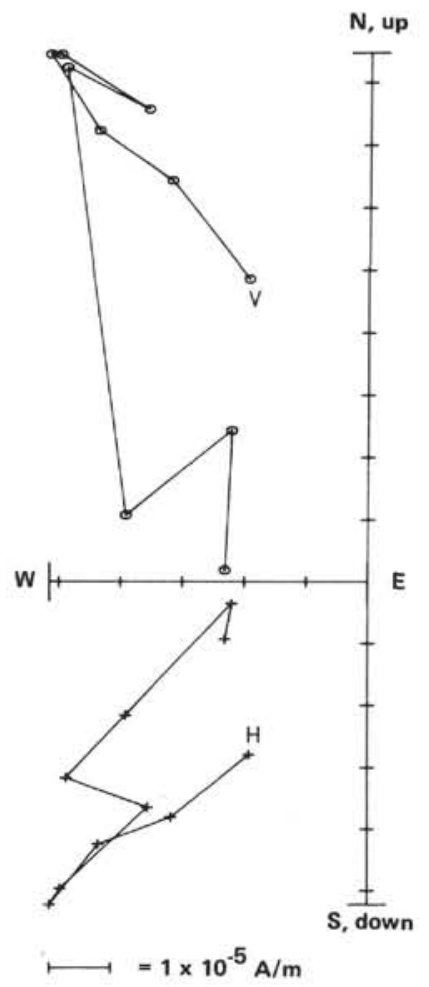

544A-14-2, $14 \mathrm{~cm}$

$\left(100-600^{\circ} \mathrm{C}\right)$

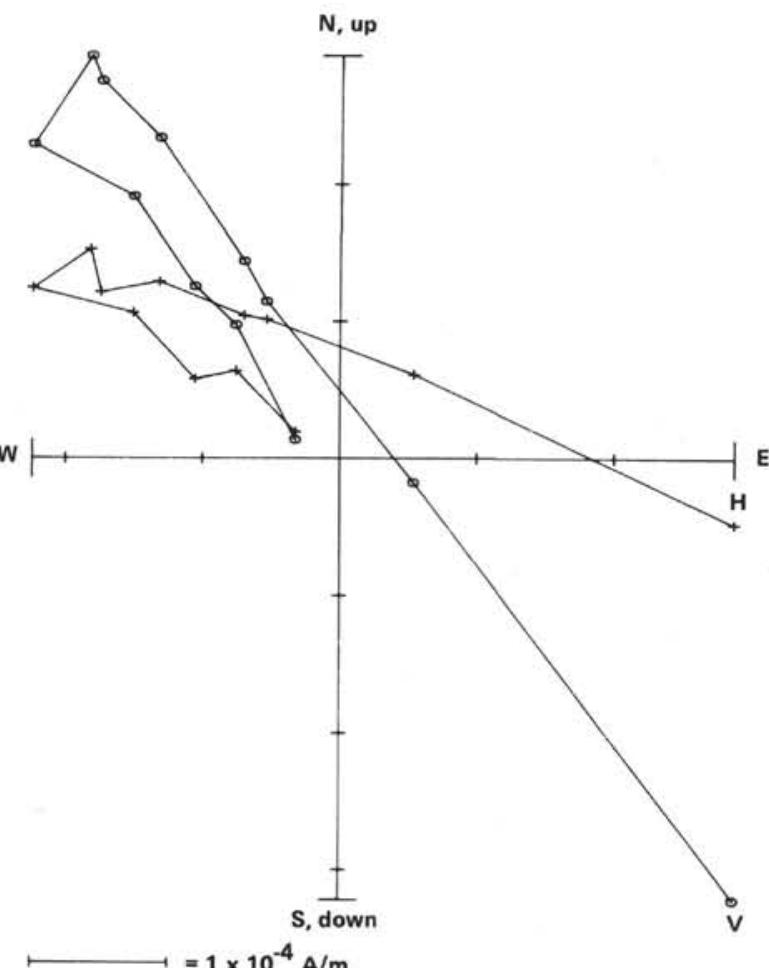

Figure 2. Orthogonal projection of thermal demagnetization data from Hole 544A, Cores 13-16. The open circles represent the vector endpoints projected to the vertical plane; the crosses represent the projection to the horizontal plane. The demagnetization steps were NRM, $100^{\circ} \mathrm{C}, 150$ to $550^{\circ} \mathrm{C}$, in steps of $50^{\circ} \mathrm{C}$, with additional steps at 575 and $600^{\circ} \mathrm{C}$ for some samples. The first and the last demagnetization stage for each plot is given in parentheses. Magnetization intensities A/m with zero intensity at the origin of the plots. The magnetization directions assume and correct for a vertical borehole. 
J. E. T. CHANNELL

544A-14-2, $93 \mathrm{~cm}$

$\left(250-575^{\circ} \mathrm{C}\right)$

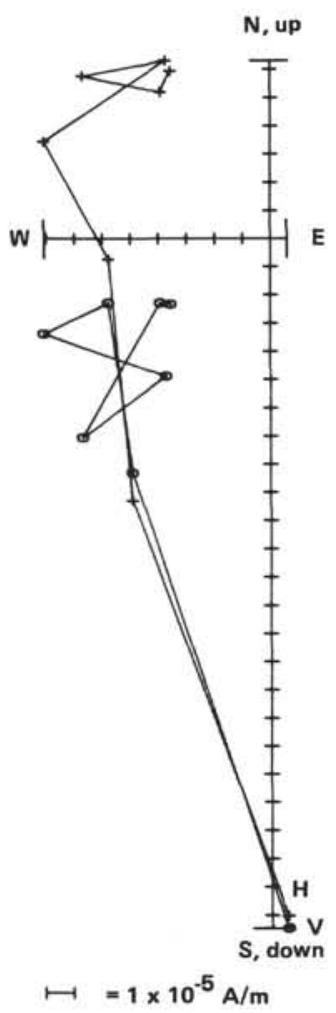

$544 \mathrm{~A}-14-3,134 \mathrm{~cm}$ (NRM-500 ${ }^{\circ} \mathrm{C}$ )

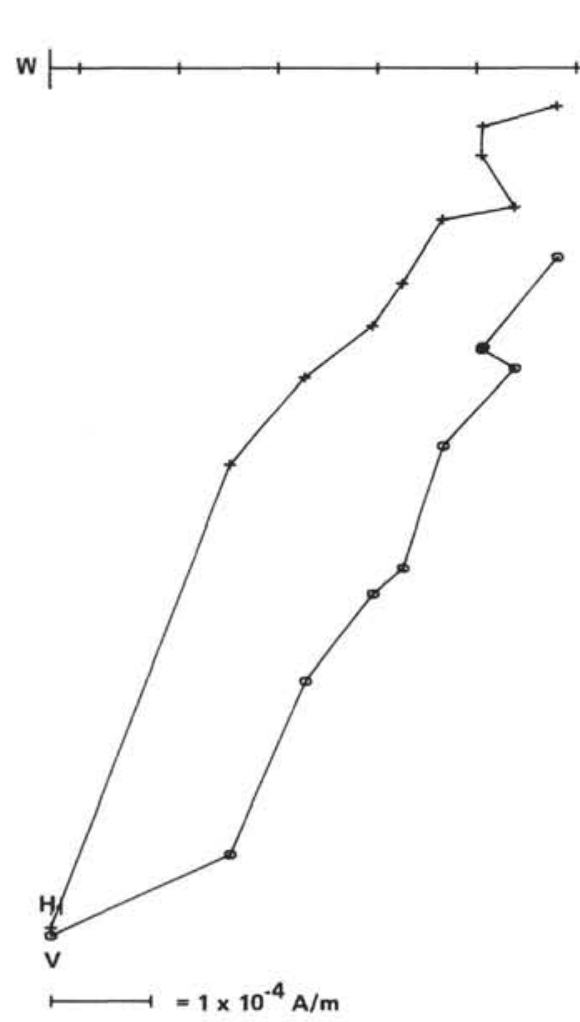

544A-14-3, $63 \mathrm{~cm}$

(NRM- $575^{\circ} \mathrm{C}$ )

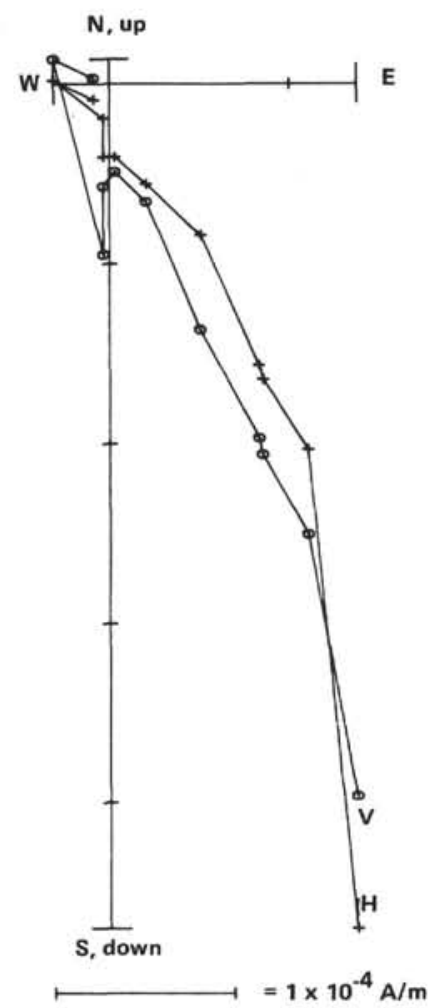

544A-14-4, $3 \mathrm{~cm}$ (NRM-575 ${ }^{\circ} \mathrm{C}$ )

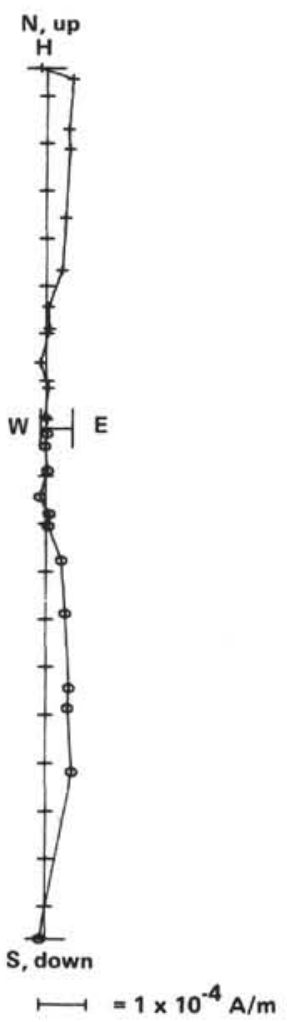

544A-14-3, $41 \mathrm{~cm}$

(NRM-600 ${ }^{\circ} \mathrm{C}$ )

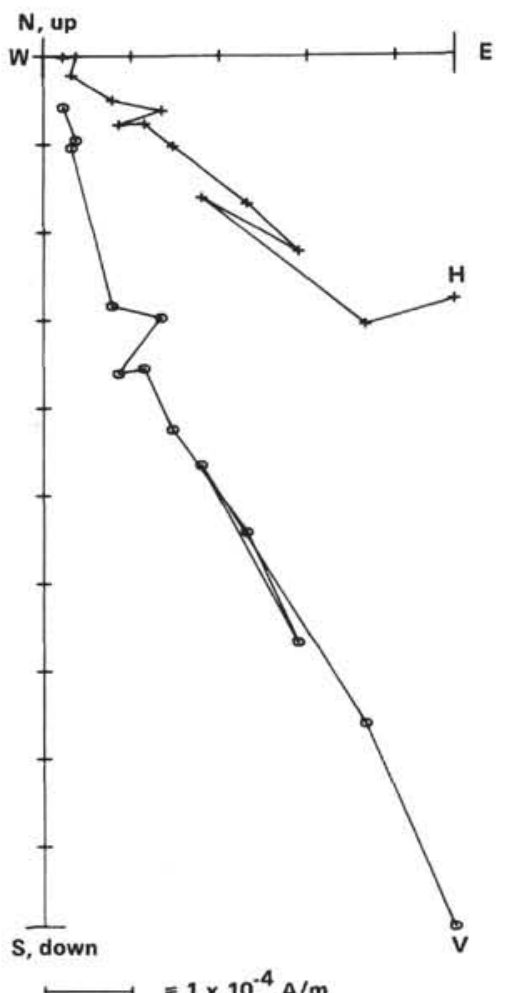

544A-14-4, $98 \mathrm{~cm}$ $\left(100-600^{\circ} \mathrm{C}\right)$

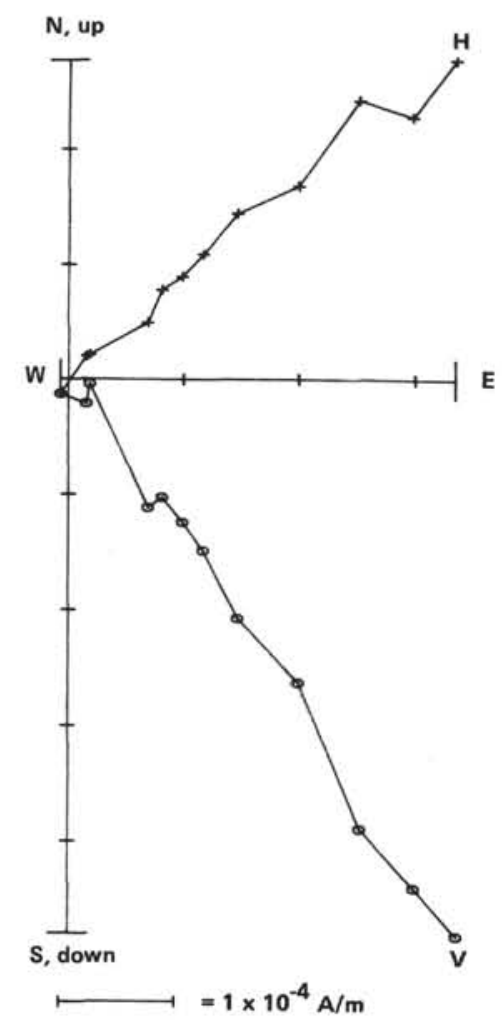

Figure 2. (Continued). 
$544 \mathrm{~A} \cdot 15 \cdot 2,29 \mathrm{~cm}$ $\left(100-575^{\circ} \mathrm{C}\right)$

$544 \mathrm{~A} \cdot 15 \cdot 3,88 \mathrm{~cm}$

$\left(100-400^{\circ} \mathrm{C}\right)$

N, up

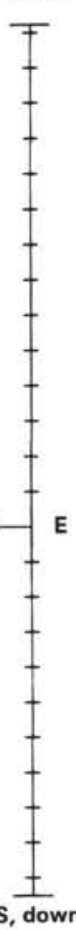

544A-15-4, $66 \mathrm{~cm}$

544A-15-3, $123 \mathrm{~cm}$ (NRM- $600^{\circ} \mathrm{C}$ )

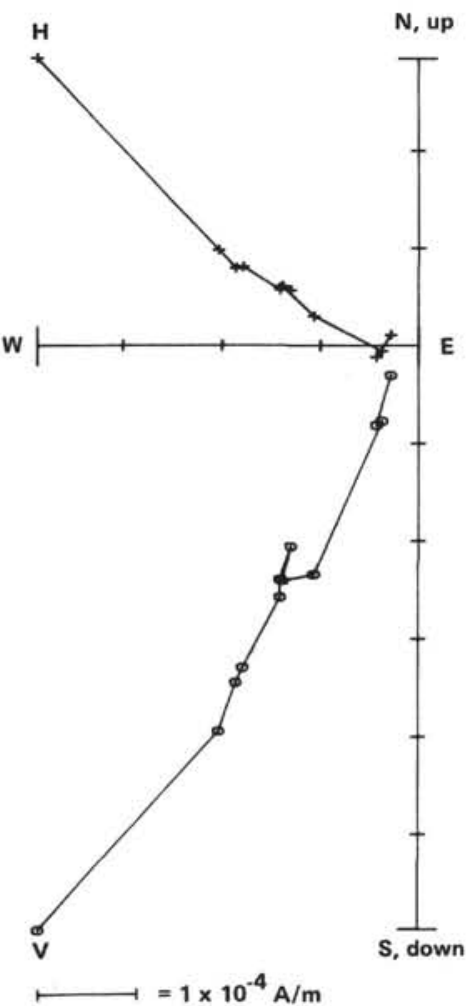

Figure 2. (Continued).

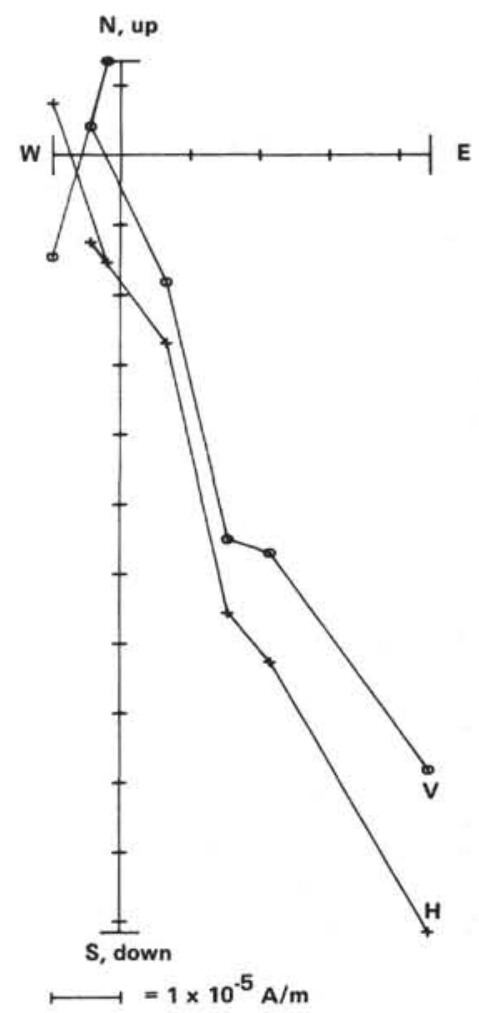

544A-16-1, $18 \mathrm{~cm}$ (NRM- $600^{\circ} \mathrm{C}$ )

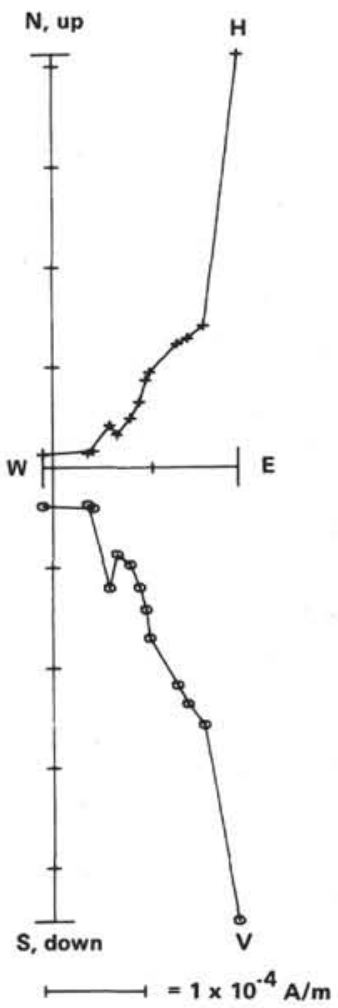




\section{HOLE 547B}

The limestones of Unit IV are very variable in lithology and are composed of light gray micritic limestones, reddish and greenish nodular limestone, limestone breccia, conglomerates, and calcareous shale. Samples were collected from various lithologies in Cores 547B-6, 547B7, 547B-8, 547B-10, 547B-11, and 547B-15 (Fig. 3). The poor recovery and high allochthonous content of the cores (limestone breccia and conglomerate) precluded the possibility of obtaining a detailed magnetic stratigraphy. However, demagnetization data from the varicolored limestone lithologies provided some interesting high quality data and a good estimate of paleolatitude.

The representative orthogonal projections of the thermal demagnetization data (Figs. 4, 5, 6) are divided on the basis of sample color. Figure 4 is from "red" limestones of various types. The reddish brown (10R 3/4$10 R$ 5/4) wackestones and conglomerates from Core 547B6 and the pale grayish red (10R 5/2) wackestones (547B$7-1,22 \mathrm{~cm} ; 547 \mathrm{~B}-7-1,61 \mathrm{~cm}$ ) of Core 547B-7 reveal a single magnetization component after thermal demagnetization at temperatures above 100 or $150^{\circ} \mathrm{C}$ (Fig. 4A). One of the samples (547B-7-1, $74 \mathrm{~cm}$ ) featured in Figure $4 \mathrm{~A}$ is lighter in color, being very light gray (N8) with only a very faint mottling of pale red. The natural remanent magnetization (NRM) intensity is about half that of its more colorful neighbors, but the blocking temperature spectrum has a similar distribution. The pale grayish red (10R 5/2) nodular limestones of Core 547B-8 have somewhat lower magnetization intensities but similar blocking temperature spectra (Fig. 4B) as the samples featured in Figure 4A. The pale brown (5YR 5/2) nodular limestone from Core 547B-15 reveals a high blockingtemperature reversed component carried, at least in part, by hematite (Fig. 4B).

Figures 5A and 5B are from "green" limestones of various types. Note that the NRM intensities are often at least one order of magnitude lower than those of neighboring red samples featured in Figure 4. The blocking temperature spectra of the green samples are also different, showing a shift to lower temperatures and reflecting the decreased importance of hematite as a contributor to the remanence. The blocking temperatures are largely below $500^{\circ} \mathrm{C}$ and magnetite is probably the main remanence carrier.

The polarity of the characteristic magnetization of most samples from Hole 547B is unambiguously normal. However, there are two intervals, one in Core 547B-6 and one in Core 547B-10, where a high temperature reversed component is present. In the case of Core 547B-10, four samples of pale grayish red (10R 5/2) nodular limestone show this reversed component (Fig. 6) and in Core 547B-6, two samples of greenish gray (5GY 7/1) wackestone show similar behavior (Figs. 5A, 6B). A cursory glance at the five orthogonal projects at the top of Figure 6 would indicate single component normal magnetizations. However, magnifications of the origins of these same projections (Fig. 6) indicate that the magnetization becomes reversed at high temperatures. In the case of the four red samples from Core 547B-10 (Fig. 6), the blocking temperatures of the reversed component are such that it must be carried by hematite. In the case of

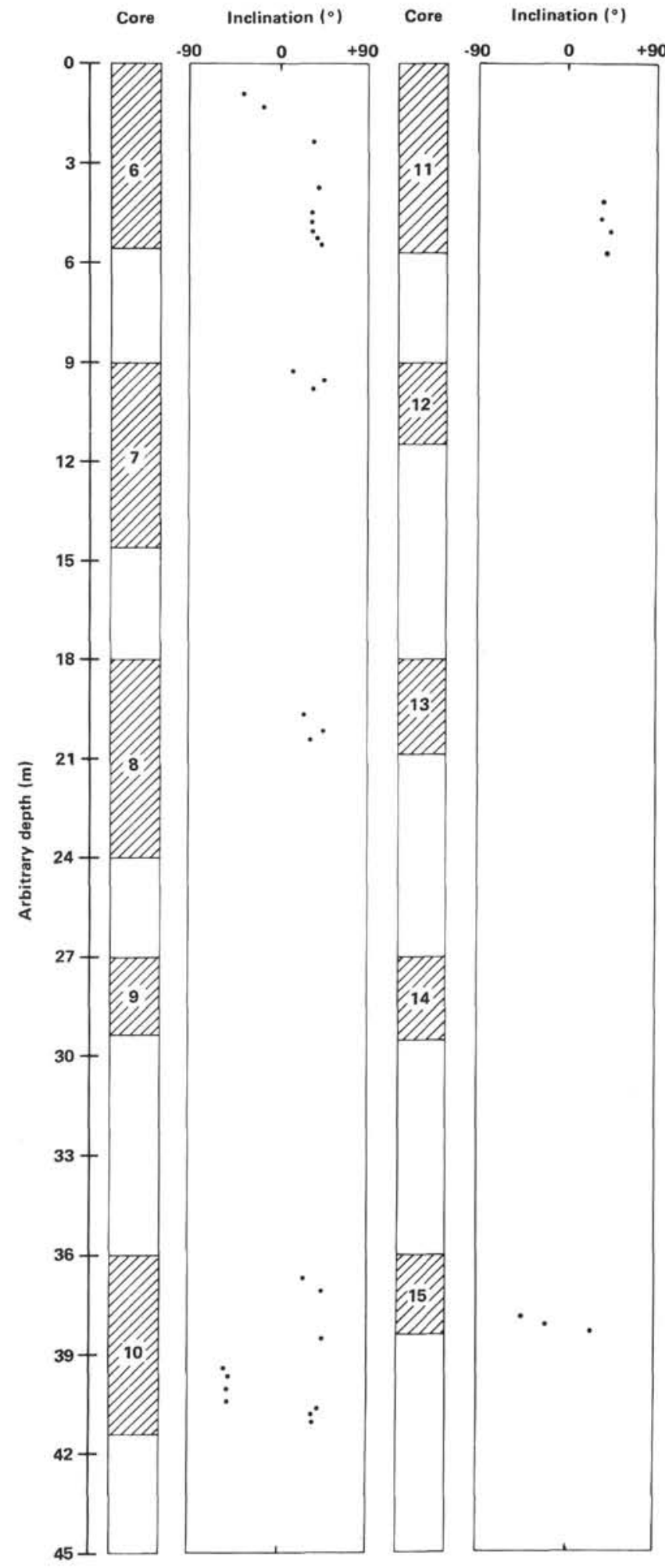

Figure 3. Inclination of the magnetization of samples from Hole 547B calculated from orthogonal projections of thermal demagnetization data.

the green samples from Core 547B-6 (547B-6-3, $75 \mathrm{~cm}$; Fig. 6B; 547B-6-1, $105 \mathrm{~cm}$; Fig. 5A), the reversed component has somewhat lower blocking temperatures. The behavior of the hematite-bearing red samples from Core 547B-10 can be explained in terms of early hematite 
growth in a reversed polarity field followed by further growth in a normal polarity field (Channell, Freeman, et al., 1982). However, the analogous behavior of the green magnetite-bearing samples from Core 547B-6 is more difficult to explain without further understanding of the magnetic mineralogy.

In order to shed light on the magnetic mineralogy of these red and green limestones, alternating field demagnetization was used to assess the coercivity of the remanence carriers. Duplicates of the samples used for the thermal demagnetization experiments were not available. Therefore, we used unoriented chips (rests) from the trimming of four samples from Cores 547B-6 and 547B10 that showed the high blocking temperature reversed component discussed above. The chips varied in size and were glued into cubic perspex containers for measurement. The red samples (Fig. 7) lose about $75 \%$ of their NRM intensities at peak alternating fields of $40 \mathrm{mT}$ (400 Oe), whereas the green samples (Fig. 8) lose about $95 \%$ of their NRM intensities at the same peak field. The difference in coercivity reflects the relative importance of hematite as a contributor to remanence. Although it is probable that the NRM in the green samples is largely carried by magnetite, hematite is most likely a major carrier of the remanence after demagnetization at peak fields of $40 \mathrm{mT}$. Therefore, we consider that in these green samples the high blocking temperature reversed component (547B-6-3, $75 \mathrm{~cm}$; Fig. 6B; 547B-6-1, $105 \mathrm{~cm}$; Fig. $5 \mathrm{~A}$ ) is carried by hematite that grew through its critical volume in a reversed epoch prior to the normal epoch (in which the detrital magnetite became aligned and further hematite growth occurred).

The characteristic magnetic inclination for each sample and the mean inclination was calculated for the green samples and for the red samples. The two mean inclinations were not significantly different at the $95 \%$ confidence level and the combined mean inclination (39. $\left.7^{\circ}\right)$ gave a paleolatitude of $22.5^{\circ}(\mathrm{dp}=5.6)$ for Hole 547B. This paleolatitude value is significantly lower than that obtained at Hole 544A. The Eastman Survey device for measuring the deviation of the hole from the vertical was not employed at Holes 544A or 547B. However, values at the Hole 547A exceeded $12^{\circ}$.

\section{CONCLUSIONS}

The magnetic properties of limestones depend on the diagenetic as well as the depositional environment. As these limestones were obviously cemented in the marine environment and have very similar magnetization properties to sediments of similar age and facies exposed on land in Italy, we may infer a similar diagenetic environment.

The presence of reversed magnetozones at both holes indicates that the age of the limestones does not lie within the Jurassic quiet zone (Callovian-Oxfordian). However, the foraminifers at Hole 547B (Riegraf et al., this volume) indicate that the reversal observed in Core 547B-6 (Fig. 3) may be Kimmeridgian and in Core 547B-10, Bajocian; these reversals bracket the quiet zone.

If we can assume that the holes were drilled vertically, the paleolatitudes are well defined.

\section{REFERENCES}

Briden, J. C., and Ward, M. A., 1966. Analysis of magnetic inclination in bore cores. Pure Appl. Geophys., 63:133-152.

Channell, J. E. T., Freeman, R., Heller, F., and Lowrie, W., 1982. Timing of diagenetic haematite growth in red pelagic limestones from Gubbio (Italy). Earth Planet. Sci. Lett., 58:189-201.

Channell, J. E. T., Ogg, J. G., and Lowrie, W., 1982. Geomagnetic polarity in the early Cretaceous and Jurassic. Phil. Trans. R. Soc. Lond., A 306:137-146.

Dunlop, D. J., and Stirling, J. M., 1977. "Hard" viscous remanent magnetization (VRM) in fine-grained hematite. Geophys. Res. Lett., 4(4):163-166.

Kono, M., 1980. Statistics of paleomagnetic inclination data. J. Geophys. Res., 85:3878-3882.

Date of Initial Receipt: December 21, 1982

Date of Acceptance: May 24, 1983 
J. E. T. CHANNELL

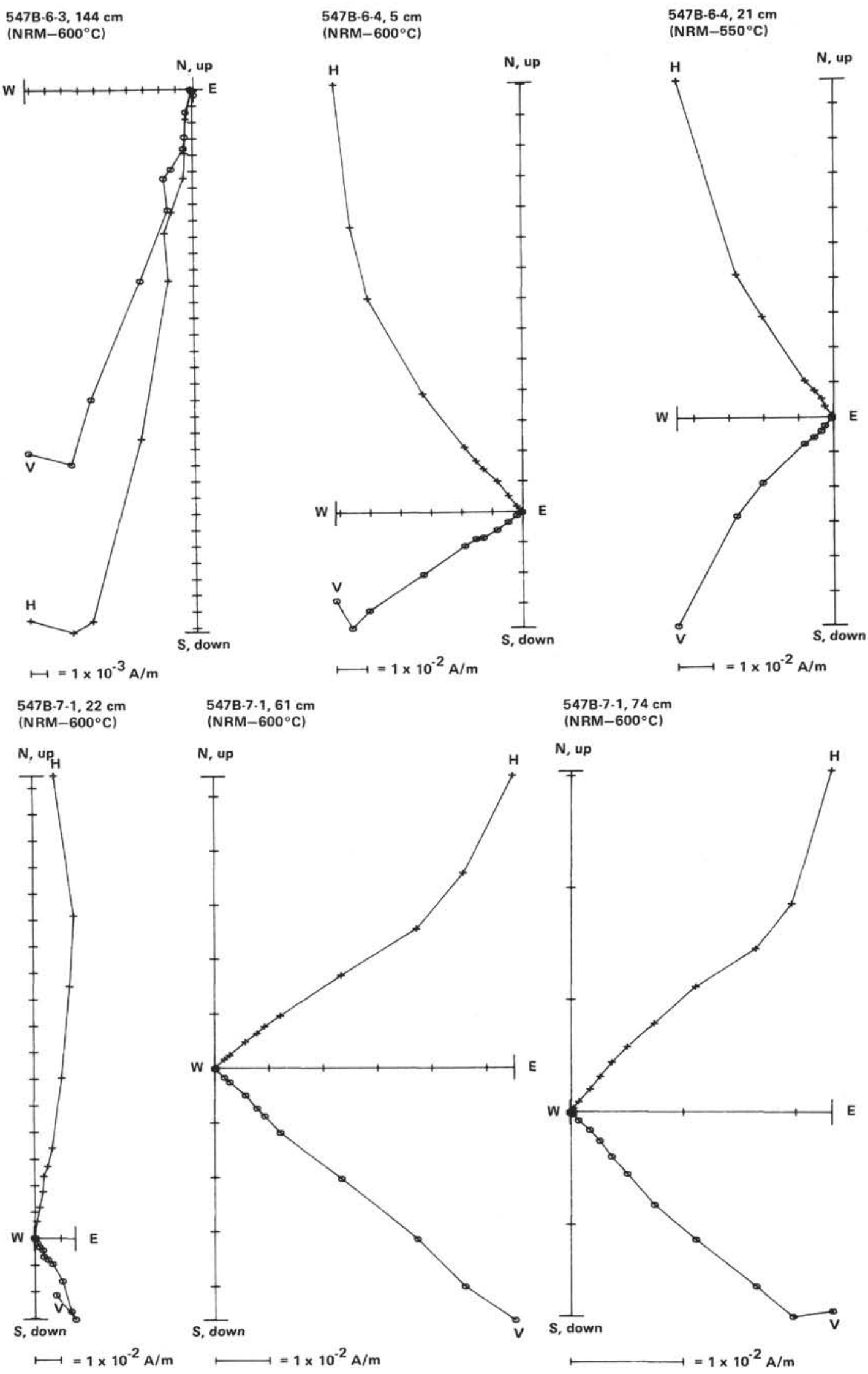

Figure 4. Orthogonal projection of thermal demagnetization data from red samples collected from Cores 547B-6, 547B-7, 547B-8, and 547B-15. (See Fig. 2 caption for notation.) 
MAGNETIZATION OF PELAGIC LIMESTONES

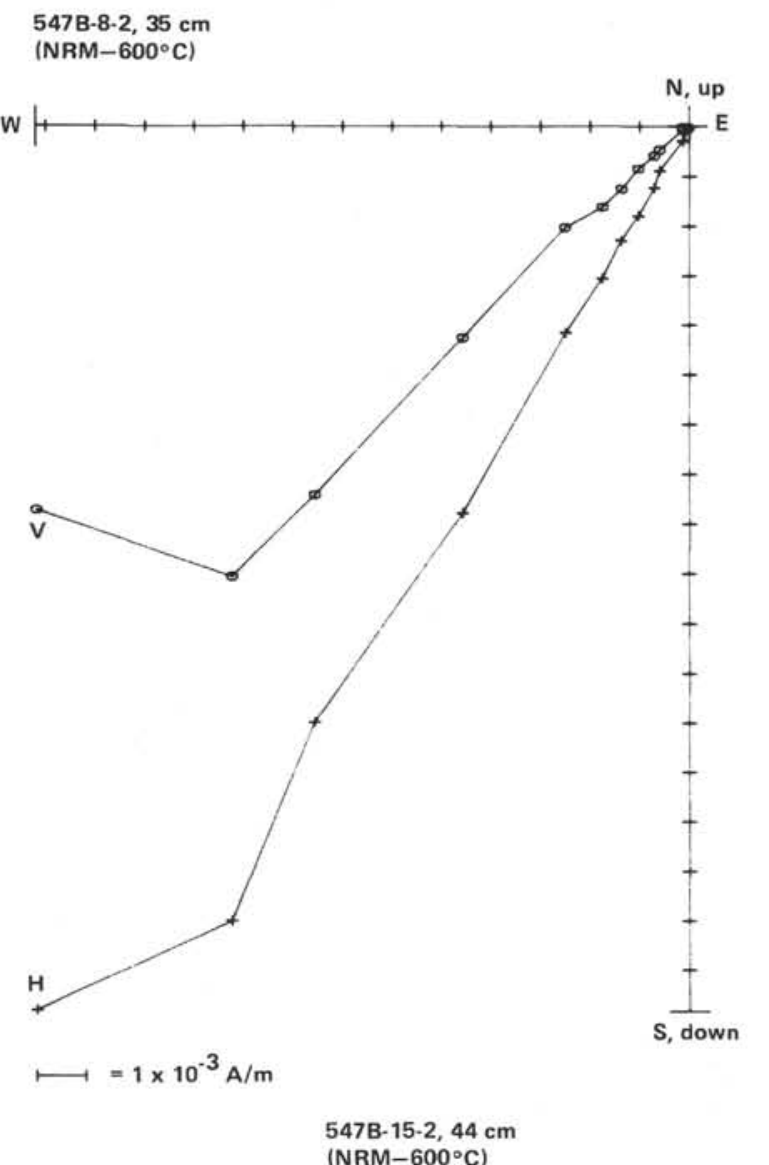

$$
\begin{aligned}
& 547 \mathrm{~B}-8-2,71 \mathrm{~cm} \\
& \left(\mathrm{NRM}-600^{\circ} \mathrm{C}\right)
\end{aligned}
$$

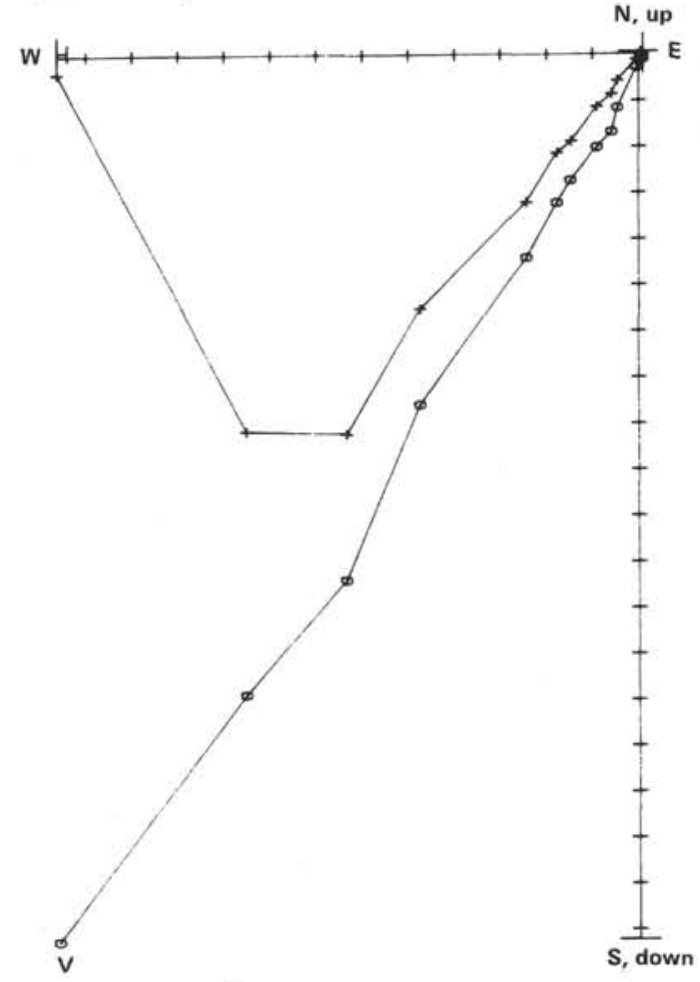

$$
\longmapsto=1 \times 10^{-3} \mathrm{~A} / \mathrm{m}
$$

N, up

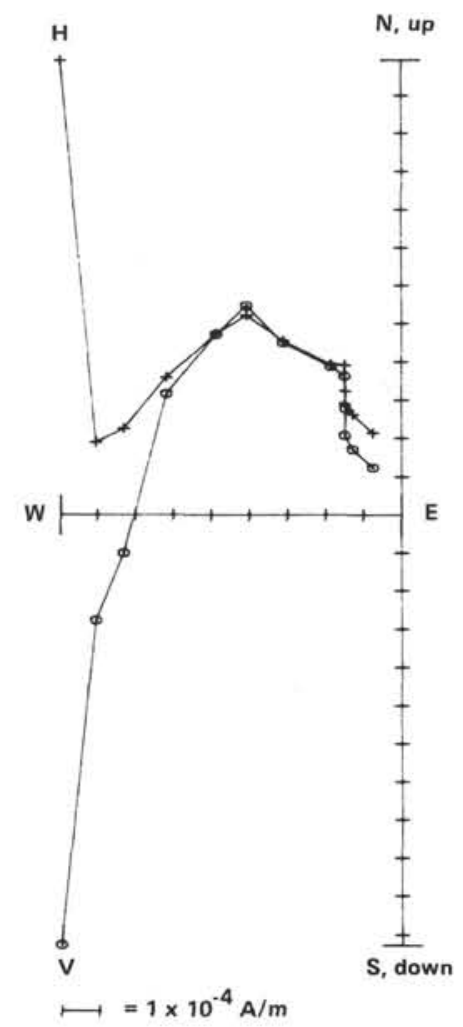

Figure 4. (Continued). 
J. E. T. CHANNELL

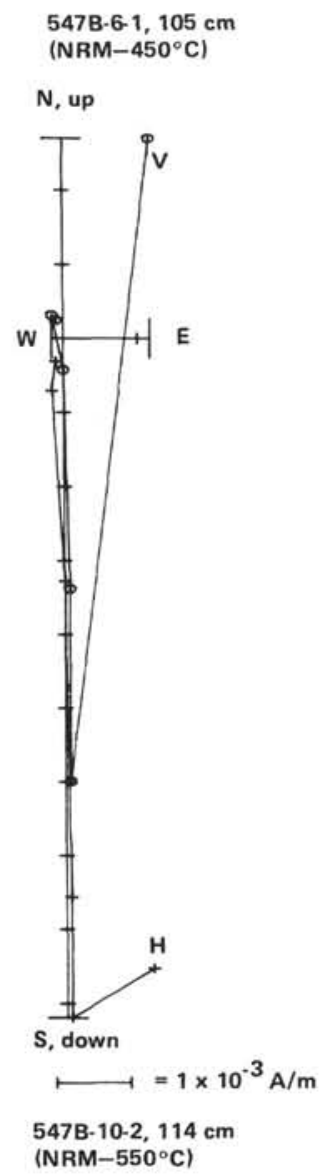
$547 \mathrm{~B}-6-2,110 \mathrm{~cm}$
547B-6-4, $52 \mathrm{~cm}$
(NRM-500 $\mathrm{C}$ )
(NRM-550 ${ }^{\circ} \mathrm{C}$ )
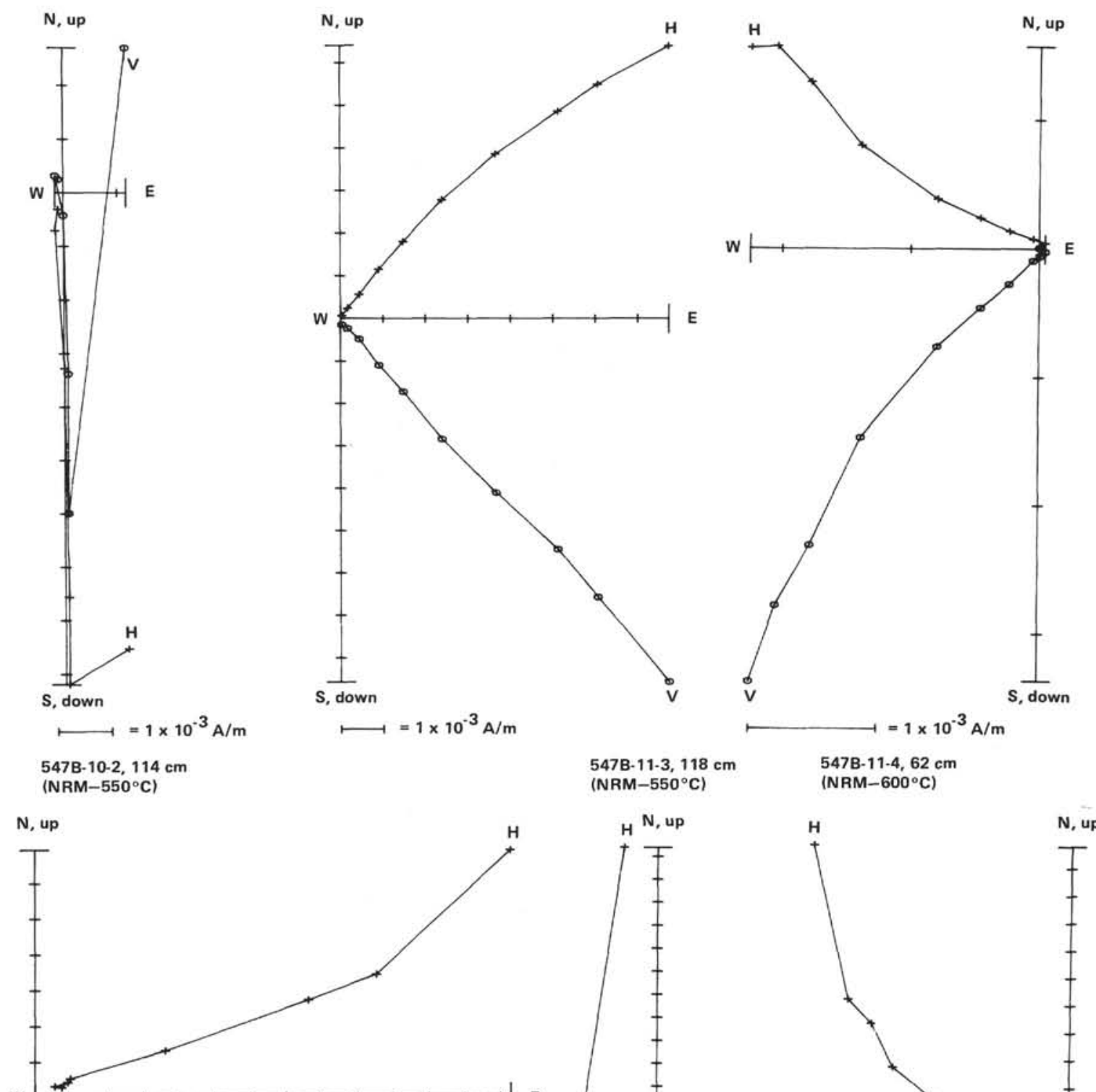

w

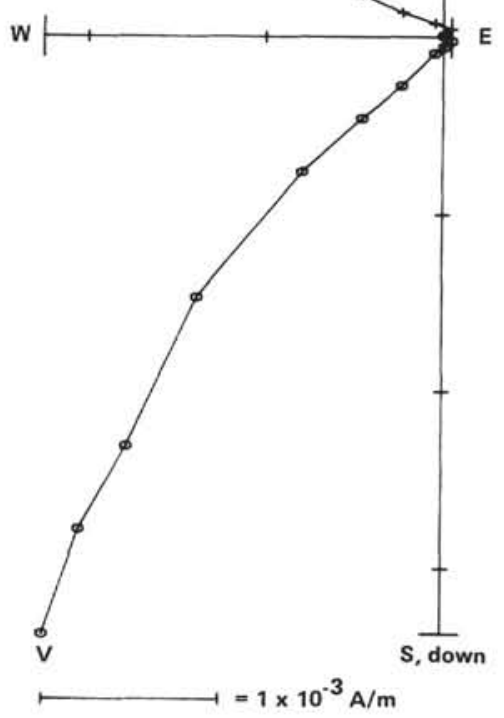

${ }_{4} \mathrm{~N}$, up
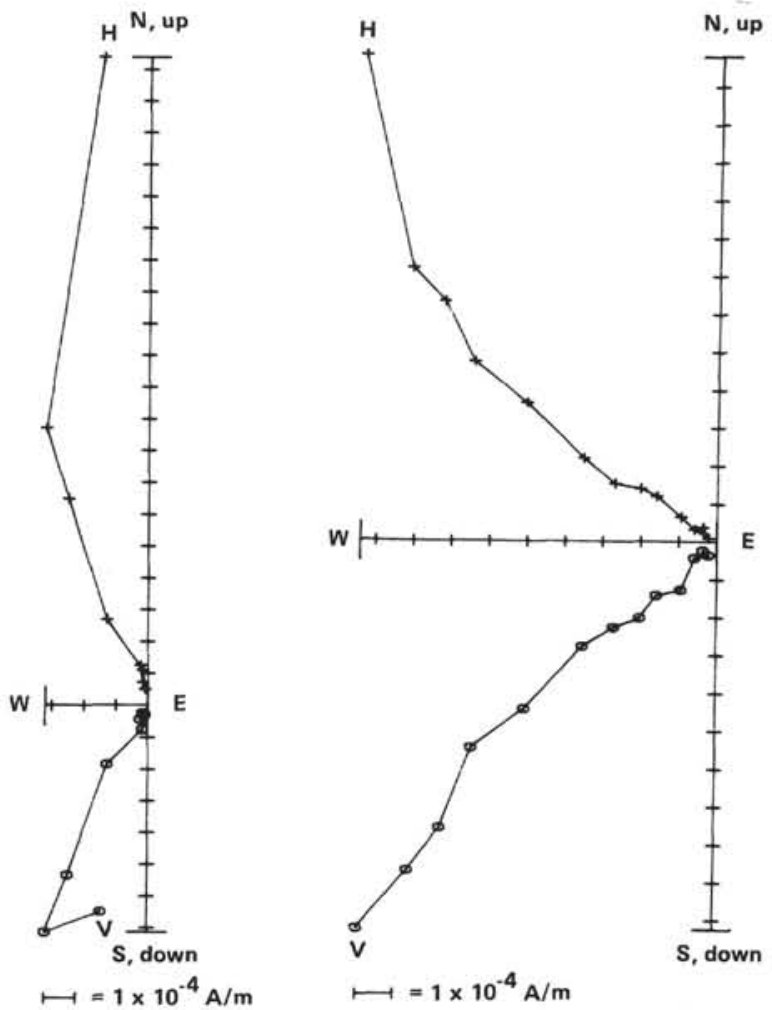

Figure 5. Orthogonal projection of thermal demagnetization data from green samples collected from Cores 547B-6, 547B-10, and 547B-11. (See Fig. 2 caption for notation.) 


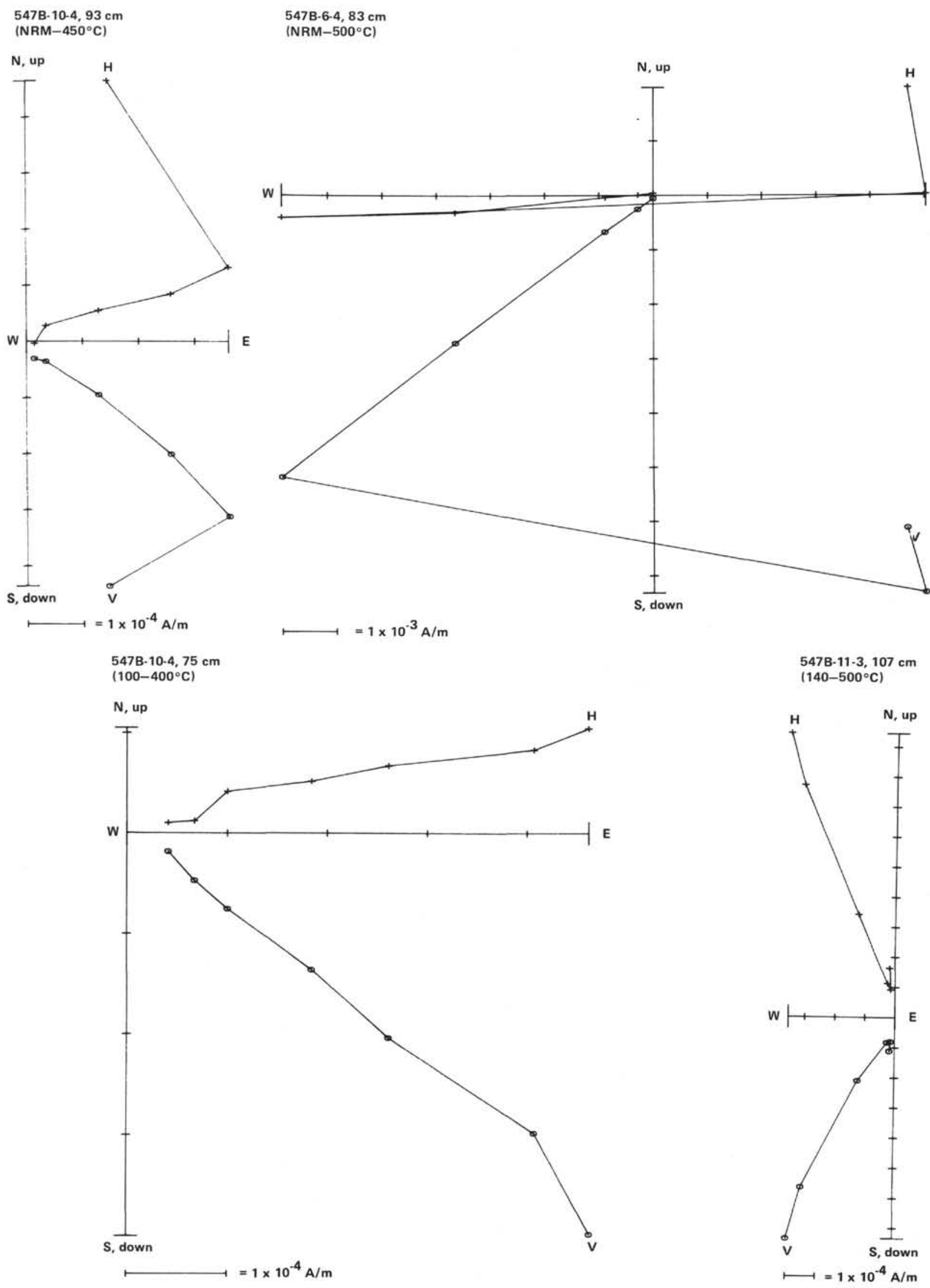

Figure 5. (Continued). 

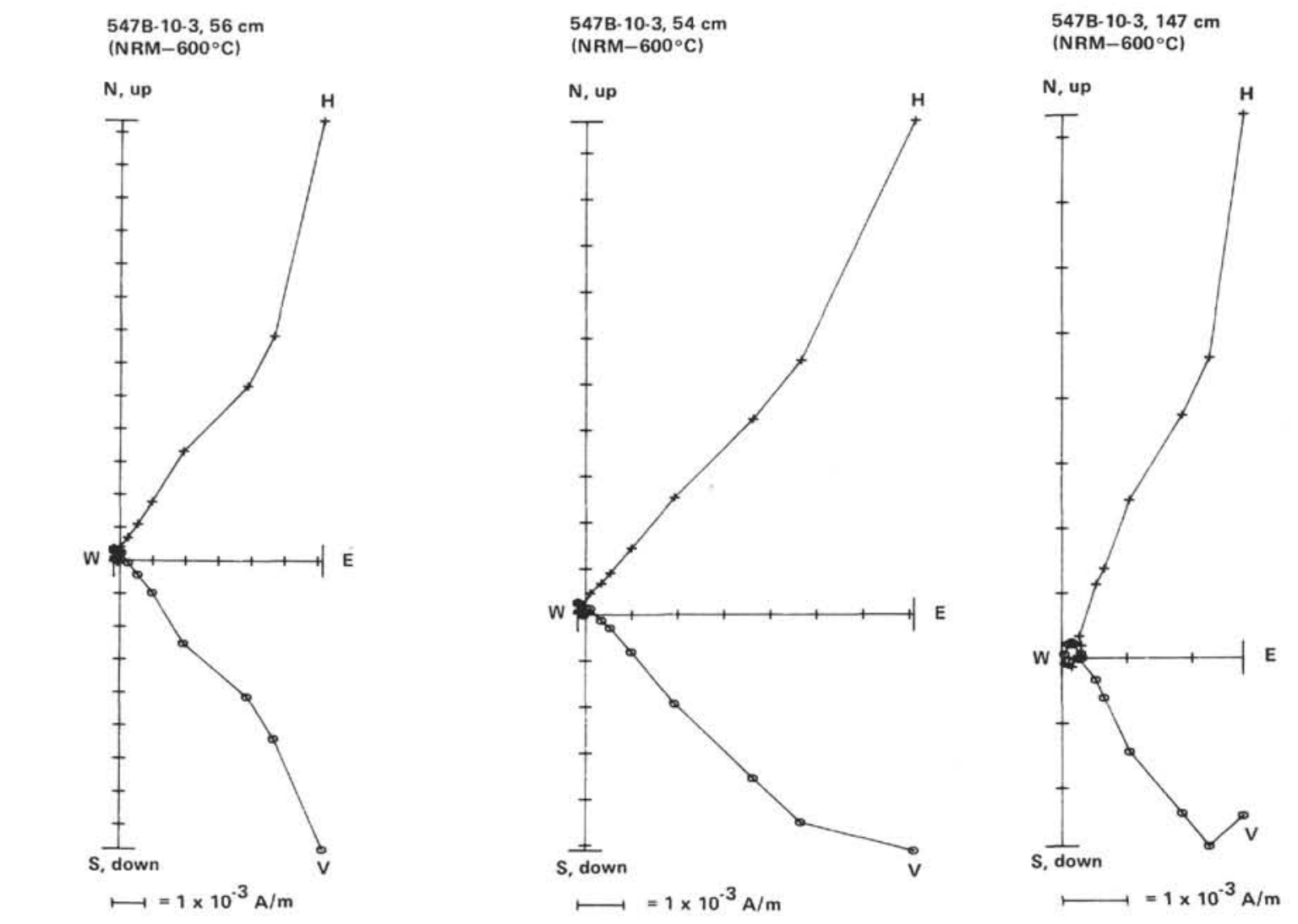

547B-10-3, $56 \mathrm{~cm}$

$$
\left(250-600^{\circ} \mathrm{C}\right)
$$

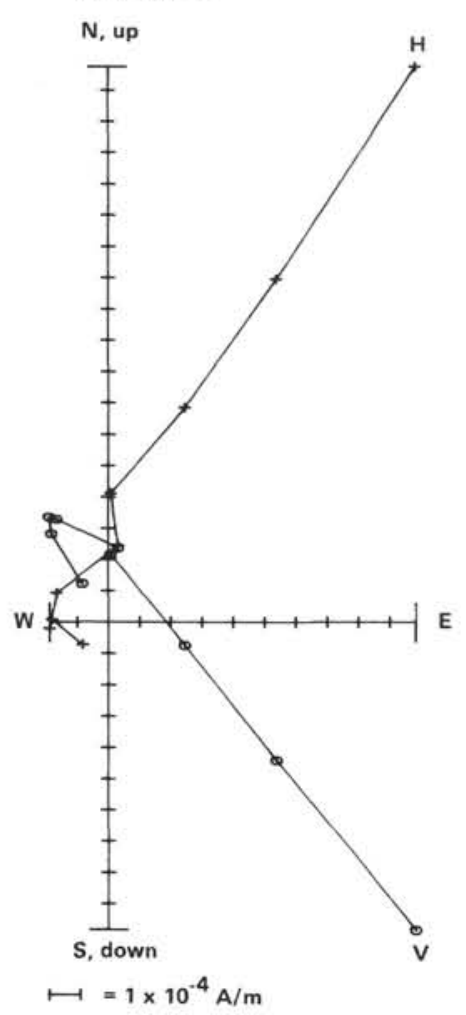

5478-10-3, $59 \mathrm{~cm}$

$\left(300-600^{\circ} \mathrm{C}\right)$

547B-10-3, $147 \mathrm{~cm}$

$\left(300-600^{\circ} \mathrm{C}\right)$
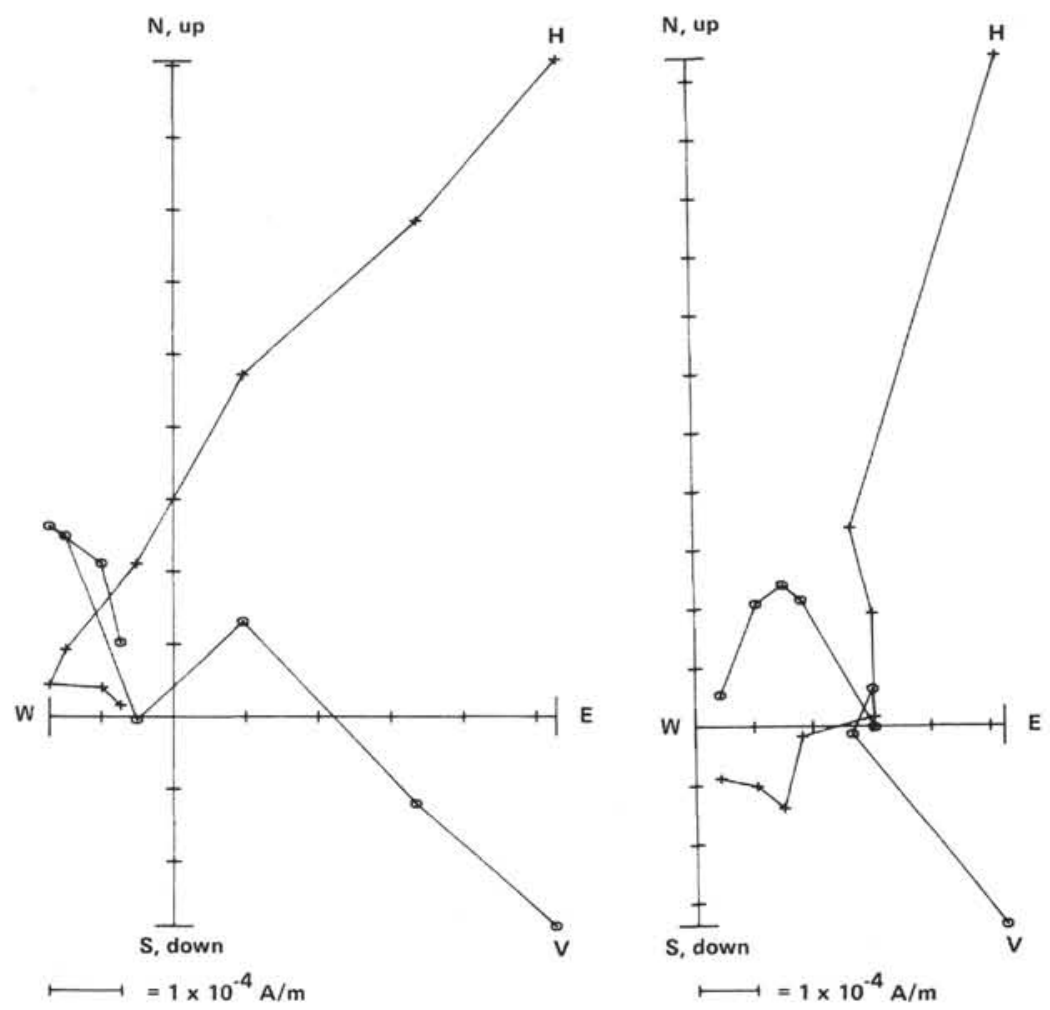

Figure 6. Orthogonal projections of thermal demagnetization data from Core 547B-10 (red samples) and Core 547B-6 (green samples). Note that the lower projections are blowups of the origins of the plots above. The first and last demagnetization stage for each projection is given in parentheses. (See Fig. 2 caption for notation.) 
547B-6-3, $75 \mathrm{~cm}$

(NRM $-575^{\circ} \mathrm{C}$ )

N, up

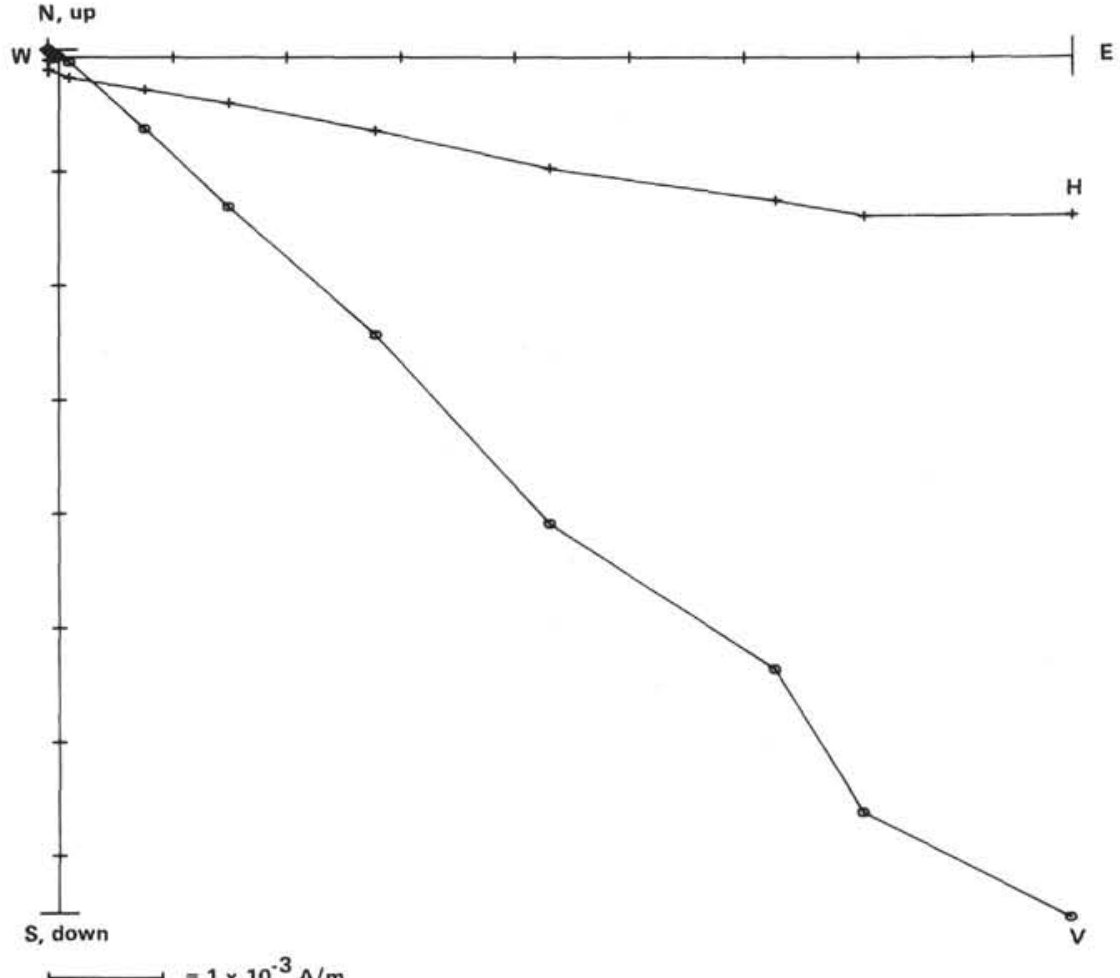

547B-6-3, $75 \mathrm{~cm}$

$\left(350-575^{\circ} \mathrm{C}\right)$

N, up
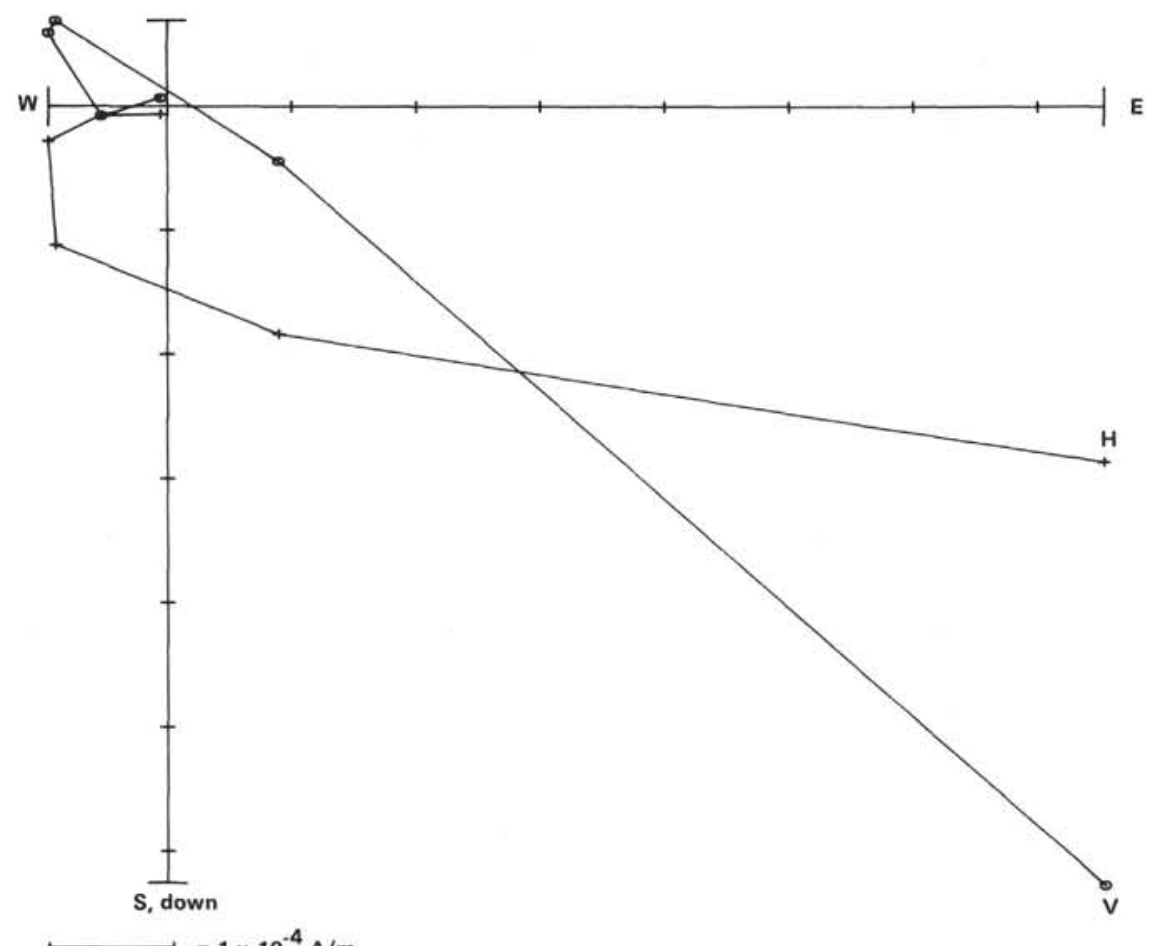

547B-10-3, $144 \mathrm{~cm}$

(NRM-550 $\mathrm{C}$ C)

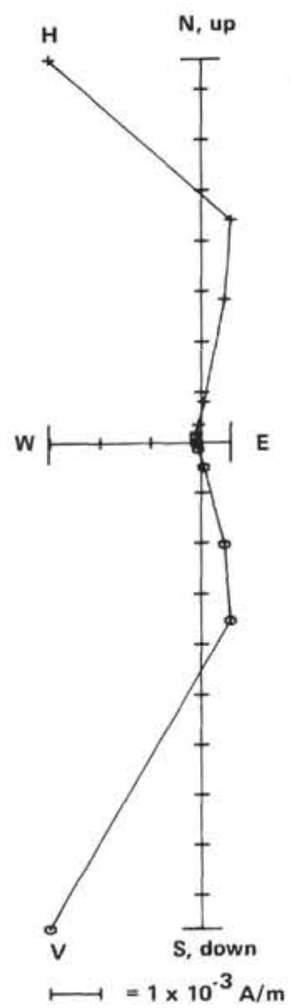

547B-10-3, $144 \mathrm{~cm}$

$\left(300-550^{\circ} \mathrm{C}\right)$

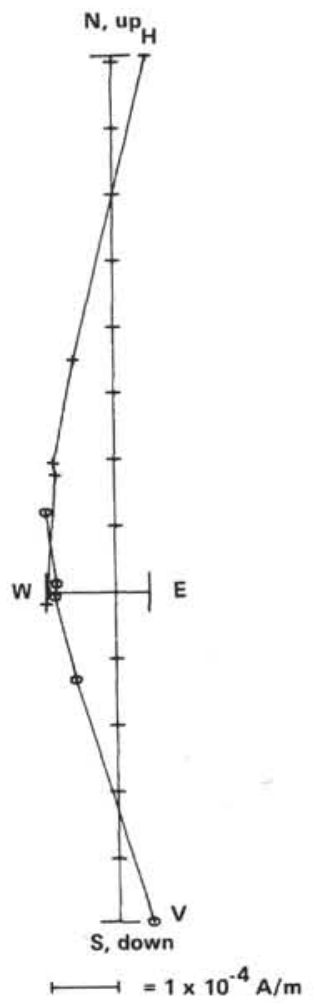

Figure 6. (Continued). 
$547 \mathrm{~B}-10-3,56 \mathrm{~cm}$ (NRM-60 mT)

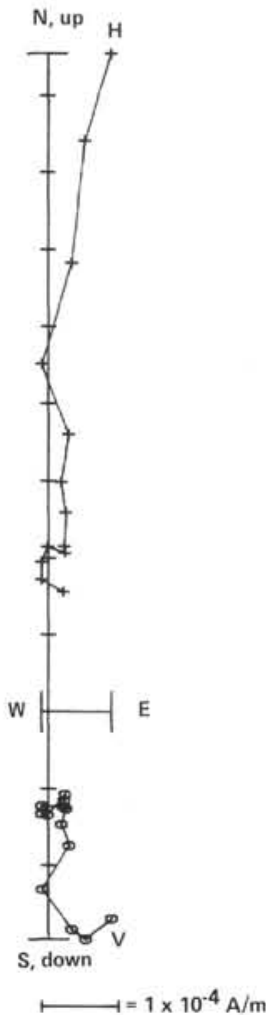

$547 \mathrm{~B}-10 \cdot 3,59 \mathrm{~cm}$

(NRM-60 mT)

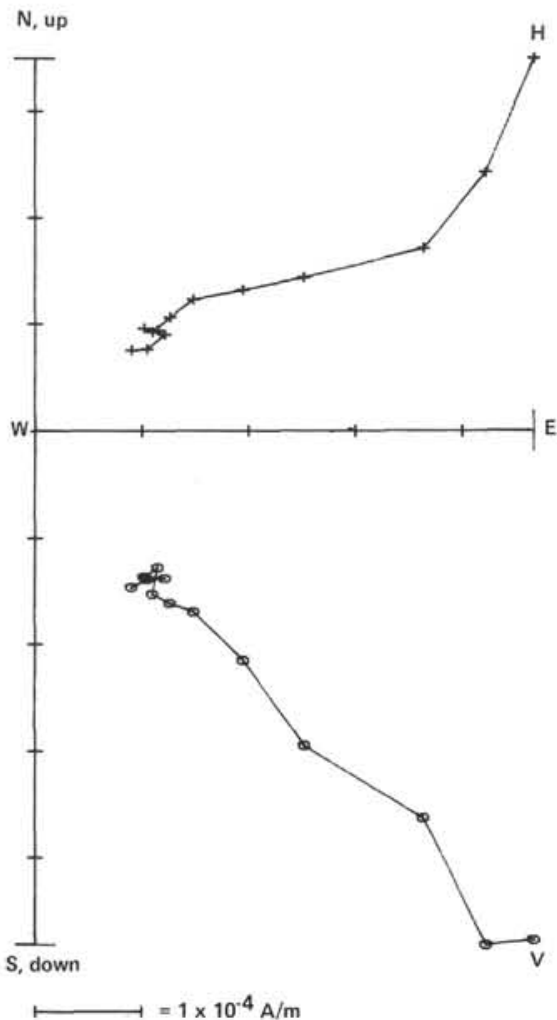

Figure 7. Orthogonal projection of alternating field demagnetization data for two red samples from Core 547B-10. The open circles represent the vector endpoints projected to the vertical plane; the crosses represent the projection to the horizontal plane. The demagnetization steps were NRM, $10 \mathrm{mT}, 15$ to $60 \mathrm{mT}$, in steps of $5 \mathrm{mT}$. The first and last demagnetization stage for each sample is given in parentheses. 
547B-6-3, $75 \mathrm{~cm}$

(NRM-60 mT)

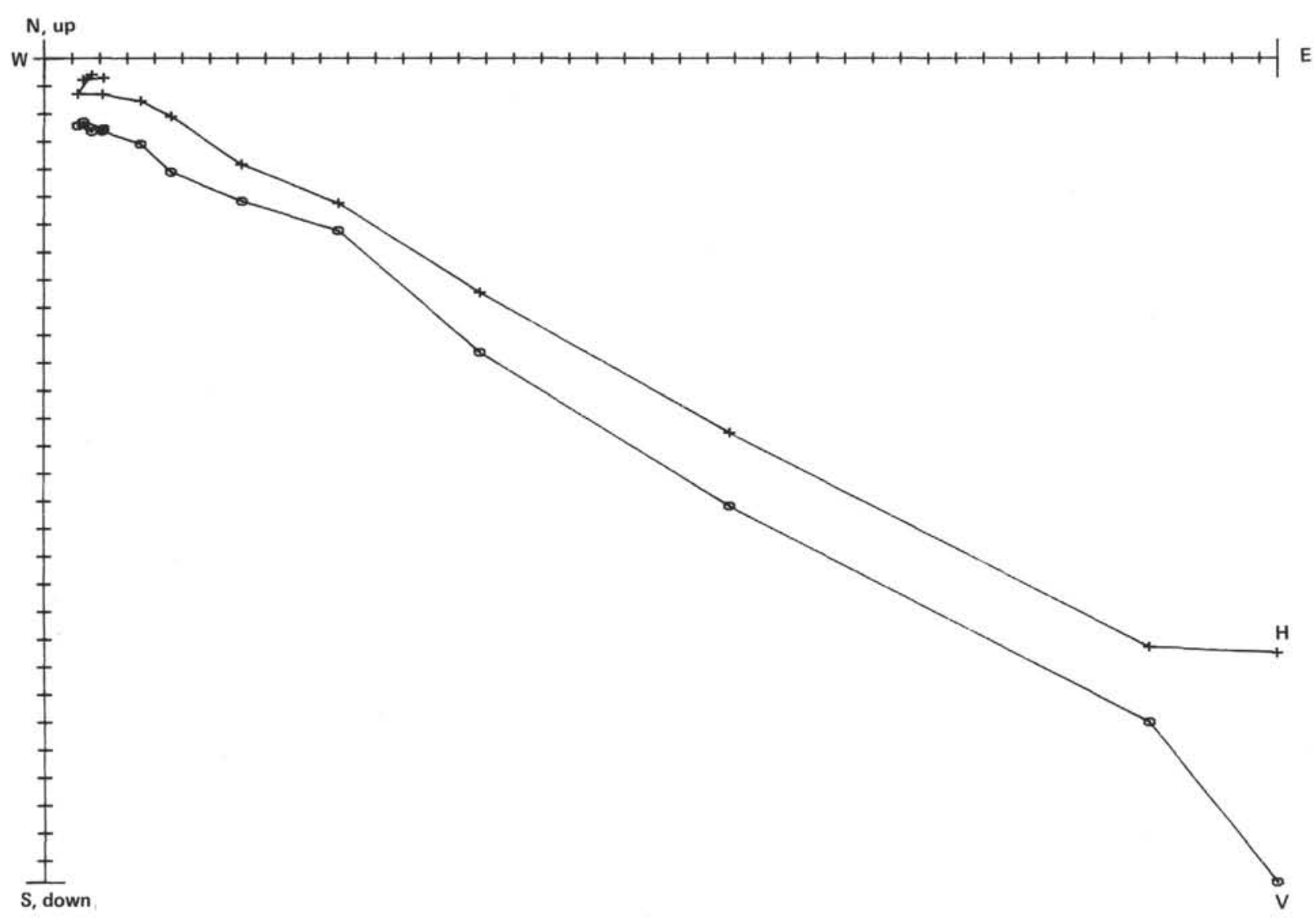

$\longmapsto=1 \times 10^{-5} \mathrm{~A} / \mathrm{m}$

547B-6-1, $105 \mathrm{~cm}$ (NRM-60 mT)

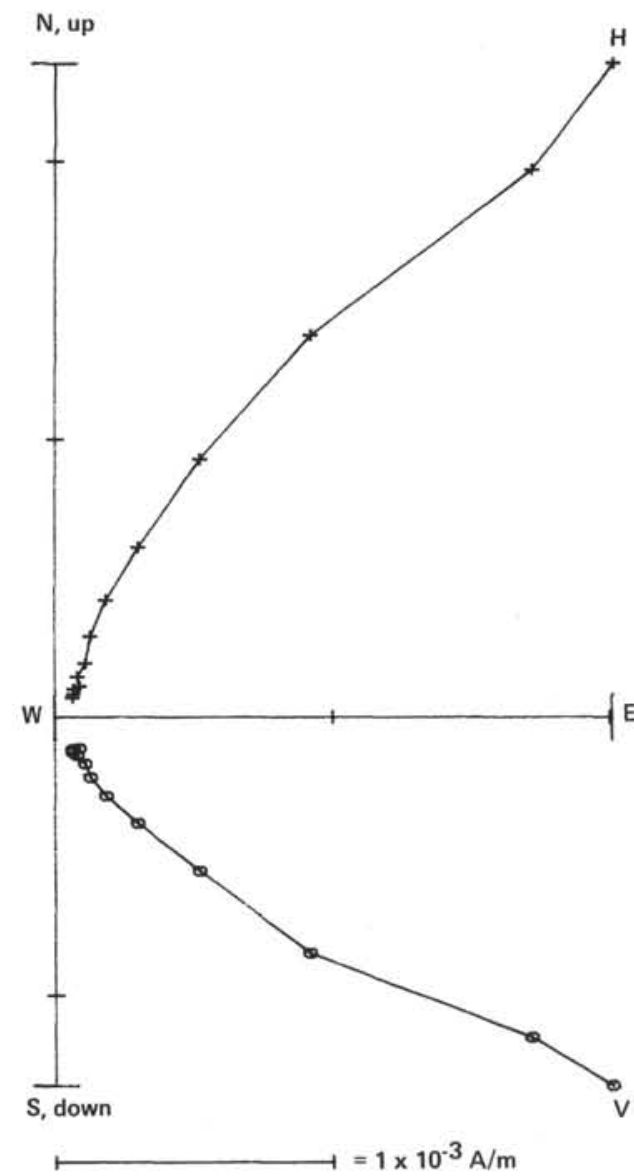

Figure 8. Orthogonal projection of alternating field data from two green samples from the core of Hole 547B. (See Fig. 7 caption for notation.) 